\title{
The role of 20-hydroxyecdysone in the CNS metamorphosis in flesh fly (Neobellieria bullata) larvae (Diptera: Sarcophagidae)
}

\author{
PETR MYŠKA and JAN ŽĎÁREK \\ Institute of Organic Chemistry and Biochemistry, Academy of Sciences, Flemingovo nám. 2, 16610 Praha 6, Czech Republic; \\ e-mail: zdarek@uochb.cas.cz
}

Key words. Ecdysteroids, metamorphosis behaviour, pupariation, Diptera, Cyclorrhapha

\begin{abstract}
The role of 20-hydroxyecdysone (20E) in the metamorphosis of the central nervous system was investigated by recording feeding, wandering and pupariation behaviour as the measures of hormonal effects on the neural tissues in the flesh fly Neobellieria (Sarcophaga) bullata. The minimum amount of food essential for the commitment to metamorphosis is rather small and constant and the larvae ingest it during the first 4 to $12 \mathrm{~h}$ of the last instar. Underfed larvae maintain food appetency for a certain time and this period of hunger can be considerably shortened by the application of $20 \mathrm{E}$. Application of $20 \mathrm{E}$ also significantly shortens or abolishes the intake of additional food offered to starving larvae. Thus $20 \mathrm{E}$ has an effect on neural mechanisms controlling both termination of the period of hunger and suppression of feeding behaviour. Application of $20 \mathrm{E}$ at any time during the wandering stage stimulates the precocious onset of pupariation. The central neurons controlling motor patterns of pupariation behaviour are committed to perform properly their programme some $15 \mathrm{~h}$ earlier than the larval integument is ready to transform into normal puparium. As a result of this temporal shift of tissue determination, some precociously formed puparia are not properly shaped despite the fact that the larva is exhibiting normal patterns of pupariation behaviour.
\end{abstract}

\section{INTRODUCTION}

Prior to their metamorphosis to the pupal stage, larvae of many holometabolous insects cease feeding and begin a period of sustained crawling or digging until they find a suitable site for pupation. The onset of this stereotypical wandering behaviour is often characterised by a dramatic switch in sensory responsiveness. This is well expressed in larvae of the cyclorrhaphous Diptera that feed on excessively wet substrates, such as decaying flesh, fruits or animal excrements, while formation of the puparium (pupariation) regularly takes place in a dry environment. If a flesh fly larva does not find a dry place, or if it is experimentally forced to remain in a wet one, the formation of puparium is postponed or abolished (Ohtaki, 1966). Injection of 20-hydroxyecdysone (20E) into such wet-treated larvae restores development and the larva forms puparium (Ohtaki et al., 1968). This suggests that the switch from preferences for wet to preferences for dry is associated with hormonal action of the ecdysteroid. Indeed, several RIA studies in various dipterans revealed a "commitment peak" of ecdysteriod(s) in the hemolymph that heralds the onset of the wandering stage (for references see Žd'árek, 1985), just as it has been documented in many other insects, mainly from Lepidoptera (Riddiford \& Truman, 1978). The amount of feeding during the early part of the last larval instar is crucial for the commitment period and subsequent ecdysis to occur (Bounhiol, 1938; Nijhout, 1975).

While in the larvae of most herbivorous insects (e.g. Lepidoptera) the critical size determining the onset of metamorphosis (and consequently the size of adults) is rather constant or in a very narrow range, in higher flies (Diptera, Cyclorrhapha) the commitment period can be achieved even after a relatively short feeding. As demonstrated in Sarcophaga or Calliphora, the weight of puparia (and the size of adults resulting from them) may be as low as $20 \%$ of that of normal flies (Žd'árek \& Sláma, 1972). As is apparent from the scheme in Fig.1, the third instar larvae never form a puparium if they are allowed to consume only a sub-critical amount of food or are not allowed to feed at all. It means that a "critical" minimum amount of feeding in the last instar is necessary to initiate development leading to metamorphosis (Žd'árek, 1985, and the references therein). However, the post-feeding period of such undernourished but criticallyfed-larvae is considerably longer than of those fed ad libitum. In Neobellieria bullata (Parker) the feeding instincts ("hunger" or "appetite") persist for a certain time following the removal from food, and only after that period does larval behaviour change to wandering mode and the larva rejects any offered food. The onset of wandering behaviour in the under-nourished larvae was accelerated by the injection of exogenous $20 \mathrm{E}$ shortly after the removal from food (Žd'árek, 1981). However, the accelerated larvae frequently did not contract properly and formed defective puparia (Žd'árek \& Sláma, 1972). Thomson \& Horn (1969) studied conditions under which such imperfect puparia were produced after administration of ecdysteroids in Calliphora stygia. They observed that larvae injected with $20 \mathrm{E}$ at a certain age formed uncontracted puparia. However, their study does not indicate at which physiological (nutritional) stage the larvae became capable of responding to a hormonal stimulus by producing normal puparia. Our barographic measurements made on the flesh fly revealed that injection of a large dose of $20 \mathrm{E}$ into late feeding or early wandering larvae could induce a complete set of motor patterns char- 


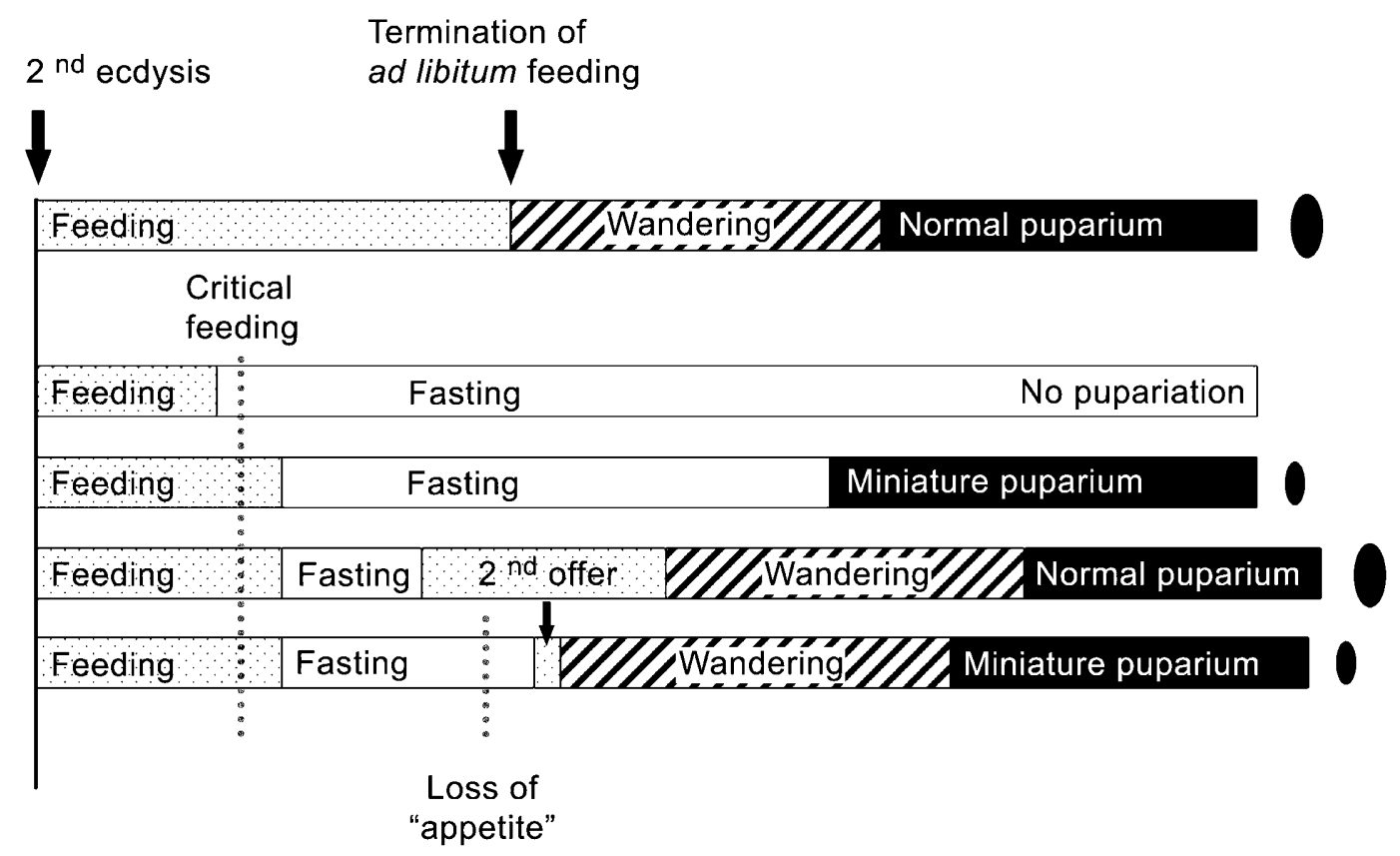

Fig. 1. The scheme of temporal relationships between feeding and wandering behaviour in normal larvae ( $1^{\text {st }}$ column) and larvae deprived of food before ( $2^{\text {nd }}$ column) and after critical feeding period without ( $3^{\text {rd }}$ column) or with opportunity to continue feeding during the period of hunger ( $4^{\text {th }}$ column $)$ and after the loss of appetite $\left(5^{\text {th }}\right.$ column $)$. The size of puparium is schematically shown at the end of each column. (Modified after Žd'árek, 1981).

acteristic of normal pupariation, even if the puparium was not properly shaped (Žd'árek, 1985). The cause of this morphological defect was attributed to the failure of the still thin cuticle to shrink properly. Our more recent findings of the importance of cuticular shrinkage for proper puparial contraction (Žd'árek et al., 2002) support this conclusion.

In the present paper we re-examine the role of $20 \mathrm{E}$ in the control of the behavioural switch from feeding to wandering and its effects on determination of motor programmes of pupariation behaviour in $N$. bullata with regard to the acquisition of competence of the integument to form perfectly shaped puparium.

\section{MATERIAL AND METHODS}

\section{Experimental flies}

Larvae of the fleshfly, N. bullata were reared by 200-300 specimens per batch on beef liver in small open disposable packets made from aluminium foil as described by Žd'árek (1980). Both the rearing and experimental rooms were kept at $25 \pm 1{ }^{\circ} \mathrm{C}$. This arrangement was very convenient for precise physiological synchronization of larvae before pupariation. Fully grown larvae that have fed ad libitum lose the feeding instinct, leave the food packets, void their crop and gut and wander in dry sawdust until they pupariate some 36 to $40 \mathrm{~h}$ later. Approximately 3 to $4 \mathrm{~h}$ before puparial contraction the region between and around the hind spiracles starts to tan. Larvae of this stage are called red spiracle (RS) larvae (Žd'árek, 1980).

Freshly ecdysed $3^{\text {rd }}$ instar larvae were selected for all experiments. They can easily be distinguished from larvae of the $2^{\text {nd }}$ instar. The surface of cuticle of the $2^{\text {nd }}$ instars is shiny and the hind spiracles possess only two fissures while the cuticle of the $3^{\text {rd }}$ instars has a dull mat surface and the spiracles are larger, having 3 fissures. Larvae used for investigation of the effects of reduced feeding were removed from the food packets after a given period of feeding and kept in petri dishes or vials with fine sawdust on the bottom. Those larvae offered additional food were returned to feeding packets and their feeding behaviour and the length of their stay on food recorded. The weighing of puparia was done shortly after pupariation. In some experiments the actual length of additional feeding was not recorded and the amount of food ingested during that period was assessed from the weight of puparium.

\section{Chemicals and injections}

20-hydroxyecdysone (20E) (99\%, Fluka) was dissolved in $10 \%$ methanol and diluted with saline in order to obtain desirable concentrations. Larvae immobilized on ice were injected with 20 E solutions by means of a disposable glass capillary with pointed tip. Control larvae received $10 \%$ methanol. The volume of injected solutions was $1 \mu \mathrm{l}$.

\section{Contact tensiometric measurements}

A non-invasive tensiometric technique of indirect detection of cuticular tension was used as previously described (Žd'árek et al., 2002). Changes of cuticular strain caused by both the muscular activity and shrinkage of the cuticle were mechanically transduced by a strain gauge and recorded. The records served to analyse the motor programmes of behaviour and changes of mechanical properties of the cuticle during pupariation. Distinctive patterns of muscular contractions that characterise particular phases of pupariation behaviour (locomotion, immobilisation, retraction, contraction) are reflected in rapid reversible pulsations of hemocoelic pressure. Shrinkage and loss of plasticity of the sclerotising cuticle cause a slow irreversible increase of the baseline. In normal pupariation the pressure changes show patterns typical for each phase of pupariation behaviour, as they were characterised by Žd'árek et al. (2002). Aberrant patterns of abnormal pupariation show variations ranging from a complete lack of phase-specific pressure fluctuations to a varying degree of simplification of the pulsation. If the cuticle fails to shrink the baseline does not increase. 


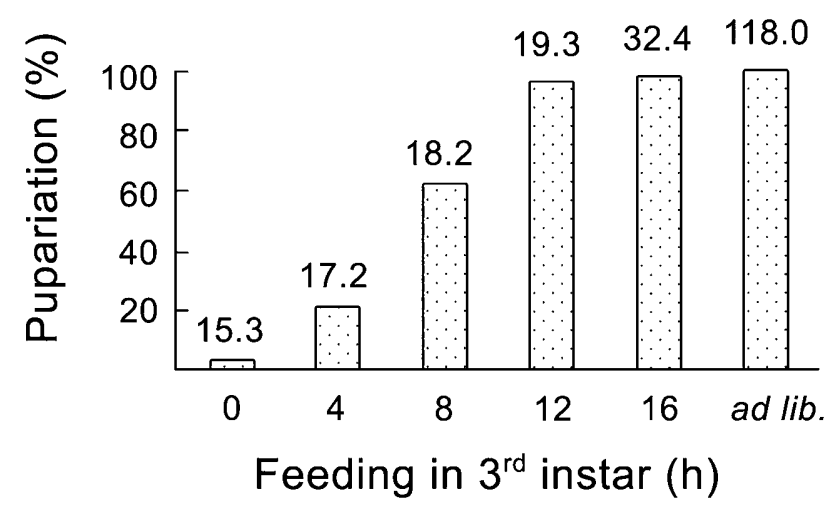

Fig. 2. The rate of pupariation of flesh fly larvae allowed to feed for various periods after the second ecdysis and those fed ad libitum. Numbers above the columns indicate the mean weight of fresh puparia in each group $(\mathrm{N}=25)$.

\section{RESULTS}

Determination of the amount of feeding critical for the commitment to pupariation

Larvae that were allowed to feed ad libitum during the first and second larval instars moulted to the third (last) instar after reaching the mass of $15.3 \mathrm{mg}$ (S.D. $=2.5 ; \mathrm{N}=$ 15). In order to continue their development towards metamorphosis they had to consume certain additional amount of food. The critical body mass at which their tissues became committed to metamorphosis was reached after they were allowed to feed for 4 to $12 \mathrm{~h}$. The mean weight of fresh puparia formed from such critically fed larvae ranged from 17.2 to $19.3 \mathrm{mg}$, while larvae allowed to feed ad libitum produced puparia of well above $100 \mathrm{mg}$ of weight (Fig. 2). The results indicate that while the intensity of feeding at the beginning of the last instar measured by the amount of food ingested by a single larva per a unit of time considerably varies among individuals, the critical amount of food essential for the commitment to metamorphosis is rather constant. For practical purposes of further experiments the last instar larvae that had been allowed to feed for $12 \mathrm{~h}$ were considered critically fed.

\section{Effects of $20 \mathrm{E}$ on the period of hunger in underfed larvae}

When food was offered after a period of starvation to larvae that had been allowed to feed for only $10 \mathrm{~h}$ at the beginning of the third instar (they consumed just about the critical amount for commitment), they resumed feeding and produced puparia of a normal size. However, if the enforced fasting lasted $32 \mathrm{~h}$ or longer, the larvae refused the offered food and formed miniature puparia (Fig. 3, marked with broken arrow). When the critically fed larvae were injected with 20E $\left(2 \mu \mathrm{g}\right.$. larva $\left.^{-1}\right)$ shortly after their removal from food, they lost their interest in food significantly sooner (after about $22 \mathrm{~h}$ ) than the controls (Fig. 3, marked with bold arrow). Thus the exogenous ecdysteroid shortened the period of hunger and accelerated the onset of wandering.

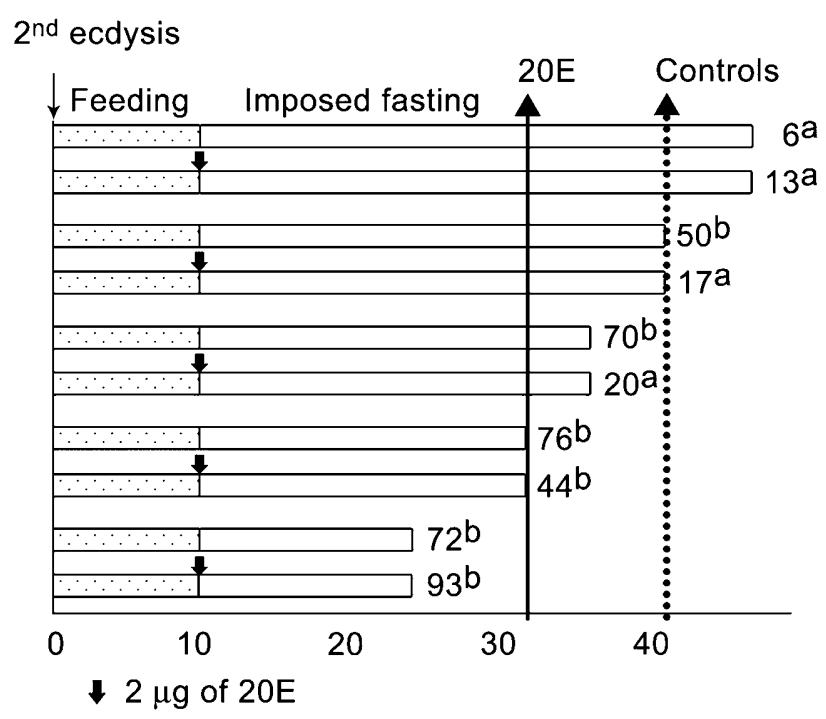

Fig. 3. The scheme of an experiment designed to study the effects of $20 \mathrm{E}$ on the duration of appetite in underfed last instar flesh fly larvae. The short arrows indicate the injection of $2 \mu \mathrm{g}$ of 20E, open column the length of imposed fasting after which all larvae were allowed to feed ad libitum, the numbers at each column represent mean weight of fresh puparia as a measure of the amount of additional food ingested (small letters indicate significance of the differences between $20 \mathrm{E}$ injected and control larvae at $\mathrm{p}=0.05, t$-test), and the upward pointing arrows show the time of the lost of appetite in ecdysone treated (full line) and control (dotted line) larvae. Ordinate: hours after 2 nd ecdysis.

\section{Effects of 20E on food intake}

Last instar larvae were fed for 8,14 and $20 \mathrm{~h}$, respectively, let to fast for a constant period of $12 \mathrm{~h}$, and then offered food again. The periods of additional feeding and wandering were recorded (Fig. 4, groups B-D). In the control group the larvae were allowed to feed ad libitum (Fig. 4, group A). At the end of the fasting period a half of the larvae in each group were injected with $20 \mathrm{E}$ (10 $\mu \mathrm{g}$. larva $\left.^{-1}\right)$ and the other half with $10 \%$ methanol (solvent). In larvae that had passed the period of hunger at the time of injection (group B) the ecdysteroid shortened the wandering stage similarly as it did in the ad libitum fed controls (group A). In larvae that still possessed the feeding instincts at the end of the fasting period (groups C, D), the hormonal treatment either abolished (group C) or shortened (group D) the periods of additional feeding in comparison with controls. Duration of the wandering period was shortened only in hormonally treated larvae of the group $\mathrm{C}$, in which additional feeding was abolished.

\section{Effects of 20E on the wandering stage, pupariation behaviour and puparial morphology of underfed larvae}

Larvae of the third instar were allowed to feed respectively for 12, 20 and $30 \mathrm{~h}$, or ad libitum and either immediately or after a period of fasting they were injected with various doses of $20 \mathrm{E}(1,2.5,5,10,20 \mu \mathrm{g})$. Control cohorts received $10 \%$ methanol. Duration of the wandering stage was measured and morphology of the 


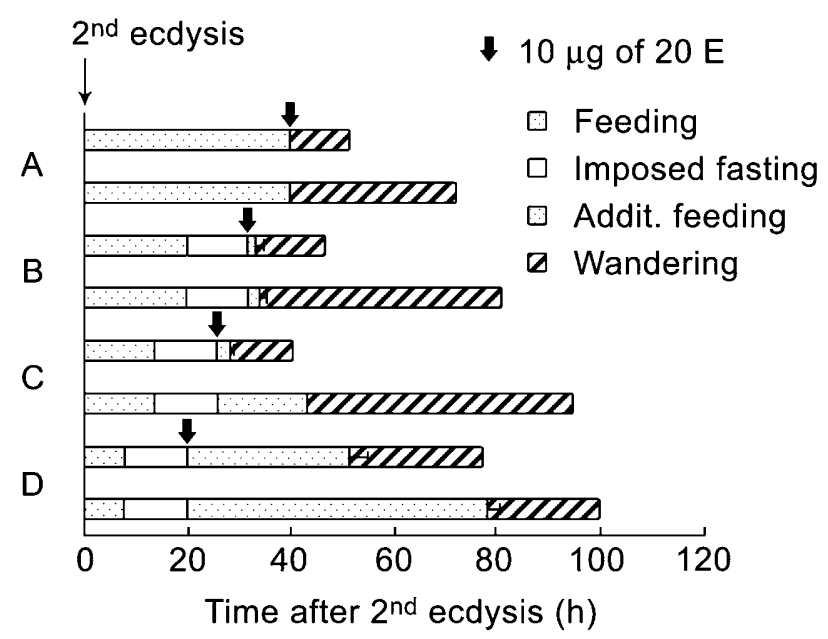

Fig. 4. The scheme of an experiment in which flesh fly larvae were allowed to feed (dotted columns) for various periods after the second ecdysis and after $12 \mathrm{~h}$ of fasting (open columns) offered additional food. The arrows indicate injection of $10 \mu \mathrm{g}$ of $20 \mathrm{E}$. Obliquely hatched columns indicate the wandering period.

puparium recorded. In selected individuals the motor patterns of pupariation behaviour were tensiometrically recorded. (Table 1). The results can be summarized in the following statements: (i) $20 \mathrm{E}$ accelerated pupariation with sensitivity increasing with prolongation of feeding. (ii) Proper morphology of the puparium was not achieved in larvae with accelerated pupariation, no matter how much food they had consumed. Notable exceptions were larvae that were fed for $30 \mathrm{~h}$ and hormonally treated $17 \mathrm{~h}$ later and those fed ad libitum and treated not earlier than after $15 \mathrm{~h}$ of wandering. (iii) Normal patterns of muscular activity, as expressed in tensiograms, were recorded in larvae fed for $30 \mathrm{~h}$ and ad libitum and injected immediately afterwards. However, the tensiograms of accelerated puparia did not show elevation of the pressure baseline, which is normally caused by shrinkage of the cuticle. This suggests that the neural centres for performance of the motor patterns of pupariation behaviour are committed to metamorphosis sooner than the integument. The results of injection of $10 \mu \mathrm{g}$ of $20 \mathrm{E}$ are diagrammatically shown in Fig. 5.

\section{DISCUSSION}

It is generally agreed that steroid hormones ecdysteroids regulate development of insect tissues through a cascade of sequential gene activation and repression. A model for ecdysteroid action proposed by Ashburner et al. (1974) assumes that the 20E-receptor complex directly induces a small set of early genes while repressing a large number of late genes. Products of the early genes then activate the late genes and suppress their own transcription. The curves of ecdysone titre during the feeding period of the last larval instar in holometabolous insects including flies show a low profile until the time when the larva stops feeding. Then an elevation known as a "commitment" peak appears. This commitment peak is consid-

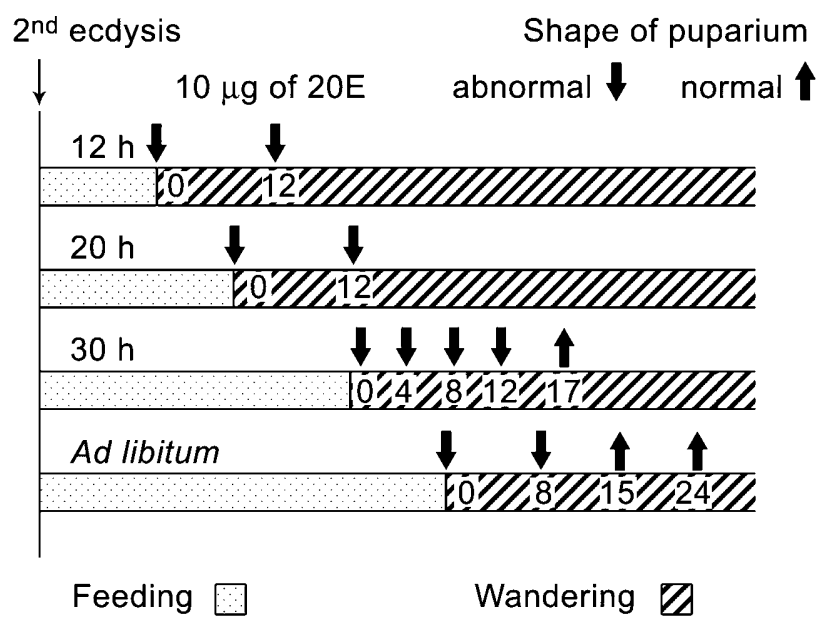

Fig. 5. The scheme of an experiment in which flesh fly larvae were allowed to feed (dotted columns) for various periods after the second ecdysis and then injected with $10 \mu \mathrm{g}$ of $20 \mathrm{E}$ at various times afterwards (oblique hatching). The arrows indicate the time of injection, its orientation means an abnormal (downwards directed) or normal (upwards directed) shape of the puparium.

ered a hormonal signal for the switch from the feeding to the wandering mode of behaviour (Riddiford et al., 2001).

Involvement of the ecdysteroids in the regulation of larval development in cyclorrhaphous flies was investigated by numerous authors already decades ago (see Žd'árek, 1985 for references). Most of them were concerned with development of the integument, namely with sclerotisation of the last instar cuticle that forms the puparium. Only the study of Shaaya \& Levenbook (1982) on Calliphora vicina was focused on larval behaviour; the authors concluded that a small peak of ecdysterones occurring in the middle of the last larval instar was responsible for the cessation of larval feeding and for gene activation, which results in the commitment of the epidermal cells to pupal differentiation. The study of Thomson \& Horn (1969) was the first to point to the fact that application of a large dose of $20 \mathrm{E}$ to $C$. stygia larvae of certain age stimulates precocious formation of uncontracted puparia. When analysing abnormal motor patterns of pupariation behaviour in larvae intoxicated with various neuroactive drugs, Žd'árek \& Fraenkel (1987) came to the conclusion that imperfect morphology of the puparium results from (i) the failure of the neuromuscular system to produce an appropriate programme of pupariation behaviour, and (ii) inability of the cuticle to shrink properly. Both the behavioural and integumental activities are under a complex neuroendocrine control, in which a pyrokinin peptide produced by the neurosecretory cells of the CNS plays a leading role (Verleyen et al., 2004). From all these results is apparent that pupariation is a well-orchestrated process requiring readiness of the neuromuscular and integumental systems for synchronised actions, which are controlled by the CNS. Hence the present study investigated the role of an ecdysteroid, 20E in determination of the nervous system for metamorphosis. 
TABLE. 1. Pupariation of last instar flesh fly larvae allowed to feed for various periods and injected with various doses of $20 \mathrm{E}$ at various times during the wandering period. ( $\mathrm{N}$ - normal, $\mathrm{A}-$ abnormal.)

\begin{tabular}{|c|c|c|c|c|c|c|}
\hline Feeding (h) & Fasting (h) & $20 \mathrm{E}(\mu \mathrm{g})$ & Wandering (h) & $\begin{array}{c}\text { Wandering } \\
\text { (\% of controls })^{*}\end{array}$ & $\begin{array}{l}\text { Morphology } \\
\text { of puparium }\end{array}$ & $\begin{array}{c}\text { Motor patterns } \\
\text { (tensiograms) }^{* *}\end{array}$ \\
\hline \multirow[t]{4}{*}{12} & 0 & 20 & lethal & & & \\
\hline & & 10 & 52 & 120 & $\mathrm{~N}$ & $\mathrm{~N}$ \\
\hline & & 5 & 52 & 120 & $\mathrm{~N}$ & \\
\hline & & 2.5 & 52 & 120 & $\mathrm{~N}$ & \\
\hline \multirow[t]{5}{*}{20} & 0 & 20 & 19 & 27 & $\mathrm{~A}$ & \\
\hline & & 10 & 31 & 67 & A & A \\
\hline & & 5 & 46 & 114 & $\mathrm{~N}$ & \\
\hline & & 2.5 & 45 & 111 & $\mathrm{~N}$ & \\
\hline & 12 & 10 & 13 & 26 & A & \\
\hline \multirow[t]{12}{*}{30} & 0 & 20 & 12 & 25 & $\mathrm{~A}$ & A \\
\hline & & 20 & 17 & 38 & $\mathrm{~A}$ & A \\
\hline & & 10 & 17 & 33 & A & \\
\hline & & 10 & 17 & 37 & A & \\
\hline & & 5 & 54 & 108 & $\mathrm{~N}$ & \\
\hline & & 2.5 & 48 & 96 & $\mathrm{~N}$ & \\
\hline & 4 & 10 & 21 & 33 & A & \\
\hline & 8 & 10 & 16 & 24 & A & $\mathbf{N}$ \\
\hline & 12 & 10 & 14 & 27 & $\mathrm{~A}$ & \\
\hline & 17 & 20 & 9 & 20 & $\mathbf{N}$ & $\mathbf{N}$ \\
\hline & & 10 & 8 & 20 & $\mathbf{N}$ & $\mathbf{N}$ \\
\hline & & 5 & 8 & 20 & $\mathbf{N}$ & $\mathbf{N}$ \\
\hline \multirow[t]{11}{*}{ ad libitum } & 0 & 10 & 11 & 34 & $\mathrm{~A}$ & $\mathbf{N}$ \\
\hline & & 10 & 10 & 26 & A & $\mathbf{N}$ \\
\hline & & 10 & 8 & 25 & $\mathrm{~A}$ & $\mathbf{N}$ \\
\hline & & 5 & 8 & 25 & A & \\
\hline & & 1 & 32 & 113 & $\mathrm{~N}$ & \\
\hline & 8 & 10 & 9 & 31 & A & $\mathbf{N}$ \\
\hline & & 1 & 13 & 43 & A & \\
\hline & 15 & 10 & 8 & 74 & $\mathbf{N}$ & $\mathbf{N}$ \\
\hline & & 1 & 7 & 66 & $\mathbf{N}$ & \\
\hline & 24 & 10 & 6 & 140 & $\mathrm{~N}$ & $\mathrm{~N}$ \\
\hline & & 1 & 6 & 140 & $\mathrm{~N}$ & \\
\hline
\end{tabular}

* bold numbers - significantly accelerated pupariation;

** bold letters - normal motor patterns in hormonally accelerated larvae.

Feeding, wandering and pupariation behaviours were used to uncover the hormone effects on the neural tissue.

It is generally known that feeding stimulates the release of hormones regulating developmental cycles in larvae. The flies are no exception. However, the amount of food, which they need for the determination of metamorphosis in the last larval instar is rather small in comparison with other insects. Our first task was to define the critical feeding period in N. bullata. We confirmed the earlier findings that the critical amount of food essential for the commitment to metamorphosis is ingested during the first few hours of the last instar (Žd'árek \& Sláma, 1972) and tends to be constant. Larvae deprived of food after the critical feeding maintain their food appetency for a certain period of time. This period of "hunger" can be considerably shortened by application of 20E. Application of the hormone to fasting larvae also significantly shortens or abolishes the intake of additional food offered to them after the injection. Thus $20 \mathrm{E}$ has an effect on neural mechanisms controlling both the termination of the period of hunger and the suppression of feeding behaviour. It should be emphasized that the effect was caused by relatively large doses of the hormone that exceeded the endogenous levels by several orders of magnitude. Small amounts of ecdysteroids cause gradual accumulation of "covert effects" of the hormones on target tissues (Ohtaki et al., 1968), which in turn cause progressive switching on of the genes responsible for individual episodes of the pre-metamorphosis and metamorphosis development. This can explain why a rather small elevation of the hormonal titre - the "commitment peak" - can trigger such a dramatic change of behaviour at the end of feeding stage, when the tissues are already sensitive to the hormone. If the "commitment peak" is produced experimentally by injecting the exogenous hormone earlier, as done in the present study, the behavioural switch from feeding to wandering and pupariation occurs sooner, apparently before other tissues are committed. This results in an imperfectly shaped puparium. Larger doses of the hormone are needed to produce the effect indicating that the tissues had not accumulated enough "covert effects". Our observation that the sensitivity of larvae to $20 \mathrm{E}$ increases with increasing length of both feeding and fasting/wandering periods (Fig. 4, Table 1) indicates that the proposed accumulation of hormonal effects is indeed a function of feeding and digestion time. 
Large doses of ecdysteroids, as a rule, stimulate precocious ecdysis with the body form corresponding to the degree of developmental determination at the time of injection (Žd'árek \& Sláma, 1972). This principle was exploited by the present study for the investigation of determination of tissues responsible for the formation of the puparium. Application of ecdysone at any time during the wandering stage stimulates the precocious onset of pupariation. However, morphologically normal puparia were produced only when the hormonal treatment was given after approximately $15 \mathrm{~h}$ of wandering. This period is required for the integument to become competent to form the smooth ovoid shape of the puparium. Interestingly, normal motor patterns of muscular activity (measured tensiometrically) were already observed in larvae treated immediately after feeding ad libitum, i.e. some 15 $\mathrm{h}$ earlier. Similarly, in underfed larvae accelerated with $20 \mathrm{E}$, normal motor patterns were recorded when the hormone was injected $8 \mathrm{~h}$ after removal from food, while a normal shape of the puparium was formed by larvae hormonally treated as late as after $17 \mathrm{~h}$ of food deprivation (Table 1, Fig. 5). This suggests that the neural centres for performance of the motor patterns of pupariation behaviour are committed to metamorphosis significantly sooner than the integument. A similar discrepancy between the time of commitment of the CNS and cuticular structures was reported by Žd'árek \& Sláma (1968) in adultoids and supernumerary nymphs of the bug, Pyrrhocoris apterus. Application of marginal doses of juvenile hormone analogues produced individuals that exhibited sexual behaviour without having differentiated external genitalia.

ACKNOWLEDGEMENTS. We thank to F. Sehnal for critical reading of the manuscript and valuable suggestions. The research project of the Academy of Sciences CR Z4 055905 was supported by the grant from the Granting Agency of the Czech Republic no. 522/01/0501.

\section{REFERENCES}

Ashburner M., Chihara C., Meltzer P. \& Richards G. 1974 On the temporal control of puffing activity in polytene chromosomes. Cold Spring Harbor Symp. Quant. Biol. 38: $655-662$.

Bounhiol J.J. 1938: Recherches expérimentales sur le déterminisme de la métamorphose chez les lépidoptères. Bull. Biol. Fr. Belg. (Suppl.) 24: 1-199.
Nishout H.E. 1975: A threshold size for metamorphosis in the tobacco hornworm, Manduca sexta. Biol. Bull. 149: 214-225.

Онтакі T. 1966: On the delayed pupation of the fleshfly, Sarcophaga peregrina Robineau-Desvoidy. Jap. J. Med. Sci. Biol. 19: $97-104$.

Ohtaki T., Milkman R.D. \& Williams C.M. 1968: Dynamics of ecdysone secretion and action in the fleshfly, Sarcophaga peregrina. Biol. Bull. Woods Hole 135: 322-334.

RidDIFORD L.M. \& TRUMAN J.W. 1978. Biochemistry of insect hormones and insect growth regulators. In Rockstein M. (ed): Insect Biochemistry. Academic Press, New York, pp. 308-317.

Riddiford L.M., Cherbas P., Truman J.W. 2001: Ecdysone receptors and their biological actions. Vitam. Horm. 60: 1-73.

ShaAyA E. \& LeVEnBook L. 1982: The role of ecdysterone in the cessation of larval feeding and the commitment to pupal differentiation in Calliphora vicina. Gen. Comp. Endocrinol. 46: 355 (Abstract).

THOMson J.A. \& Horn D.H.S. 1969: Effects of exogenous moulting hormones on puparium formation in Calliphora. Aust. J. Biol. Sci. 22: 761-765.

Verleyen P., Clynen E., Huybrechts J., Van Lommel A., Vanden Bosch L., De Loof A., Ž̄̌́́rek J. \& Schoofs L. 2004: Fraenkel's pupariation factor identified at last. Dev. Biol. 273: 38-47.

Ž ̌́ÁREK J. 1980: Neurohormonal factors involved in the control of pupariation. In Miller T.A (ed.): Neurohormonal Techniques in Insects. Springer, New York, pp. 154-178.

Ž ̌́ÁREK J. 1981: The role of hormones in the control of premetamorphic behaviour in insects. In Sehnal F. \& Zabza A. (eds): Regulation of Insect Development and Behaviour II. Technical Univ. Press., Wroclaw, pp. 993-1009.

Ž D́ÁREK J. 1985: Regulation of pupariation in flies. In Kerkut G.A. \& Gilbert L.I. (eds): Comprehensive Insect Physiology, Biochemistry and Pharmacology. Vol. 8. Pergamon Press, New York, pp. 301-333.

ŽĎ́́ReK J. \& Fraenkel G. 1987: Pupariation in flies: A tool for monitoring effects of drugs, venoms, and other neurotoxic compounds. Arch. Insect Biochem. Physiol. 4: 29-46.

ŽĎÁREK J. \& SlÁMA K. 1968: Mating activity in adultoids and supernumerary larvae induced by agents with high juvenile hormone activity. J. Insect Physiol. 14: 563-567.

ŽĎÁREK J. \& SLÁMA K. 1972: Supernumerary larval instars in cyclorrhaphous Diptera. Biol. Bull. Woods Hole 142: 350-357.

ŽĎÁrek J., MyšKa P., ZemeK R. \& Nachman R. J. 2002: Mode of action of an insect neuropeptide leucopyrokinin (LPK) on pupariation in fleshfly (Sarcophaga bullata) larvae (Diptera: Sarcophagidae). J. Insect Physiol. 48: 951-959.

Received July 14, 2004; revised October 8, 2004; accepted October 8, 2004 